\title{
Use of self-locking knots in running intestinal bariatric
} \section{sutures}

\author{
Aniceto Baltasar ${ }^{*}$, Rafael Bou ${ }^{1,2}$, Carlos Serra ${ }^{2}$, Marcelo Bengochea ${ }^{1}$ and Nieves Pérez ${ }^{2}$ \\ ${ }^{1}$ Surgery Unit, Clinic San Jorge, Alcoy, Alicante, Spain \\ ${ }^{2}$ Virgin Hospital of Lirios, Spain
}

\begin{abstract}
Bariatric suturing is a complex part of most bariatric operations. Self-locking sliding knots and Aberdeen-De Cushieri knots are very important tools to facilitate suturing.
\end{abstract}

\section{Introduction}

Laparoscopic bariatric surgery, the making of various types of anastomosis is often complex. We present a standard way of realizing the knots that shortens the operative time using continuous running suture and self-locking sliding knots.

\section{Objective}

Our philosophy in complex laparoscopic bariatric surgery is to divide any hollow organs with staplers and make anastomosis always manually. We use six ports (Figure 1), only one of them $12 \mathrm{~mm}$ in right para-rectal and allows each of the three surgeons involved to do one of the three sutures manually.

Hand suturing is a complex maneuver that must be performed carefully, with appropriate instruments and provides security in the preparation and/or reinforcement of anastomosis and space closure, using monofilament sutures to reduce the cost and time of intervention and a correct preparation of the threads facilitate implementation.

\section{Method}

The scrub nurse makes a simple running noose $[1,2]$ sliding knot (Figure 2), which passes into the abdomen and by simply pulling

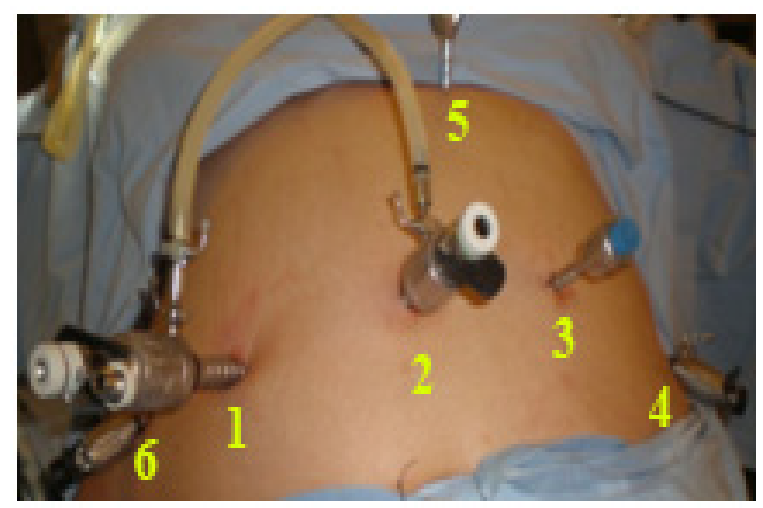

Figure 1. Situation of the ports. the thread the knot is made. For many years we have been using the self-sliding knot in all type of sutures, in all type of tissues, both in open closures of fascias and in surgery of hollow organs, open and laparoscopic, without any incident or failure.

The Aberdeen -De Cushieri knot [3], that we already present in the SECO-2004 Meeting Valladolid, ends all suture lines. They use running continuous sutures, either to reinforce staple lines or to perform complete anastomosis.

This Videos shows how both type of knots are made in the following conditions: 1) Over-suture of duodenal stump in the Duodenal Switch (LDS); 2) Over-suture of the staple-line in the Sleeve-forming gastrectomy (SFG), 3) Jejunum-jejunal anastomosis of the LDS; 4) duodenal-ileal anastomosis in the LDS and is also used to close the mesenteric defects.

\section{1. https://www.youtube.com/watch?v=mh5gDPF5zhg}

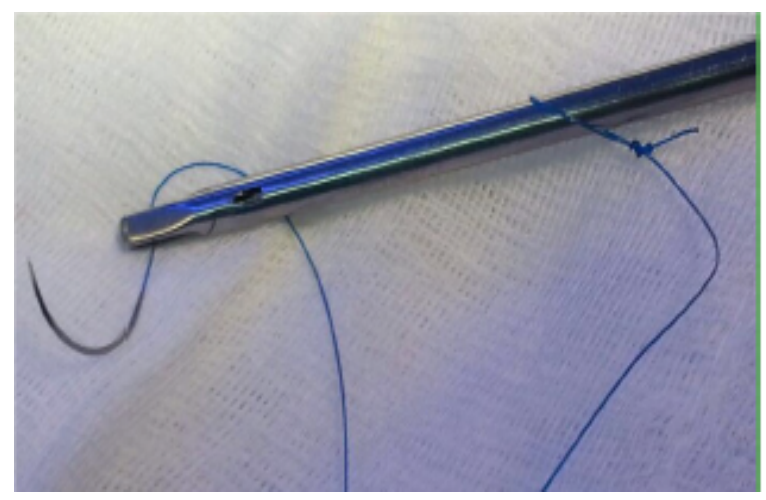

Figure 2. Needle-holder with the knot already made

Correspondence to: Aniceto Baltasar, Surgery Unit, Clinic San Jorge, Alcoy, Alicante, Spain, Tel: 0034-966.525.649; E-mail: abaltasar@coma.es

Key words: self-locking sliding knot, Aberdeen-De Cushieri, bariatric suturing

Received: March 06, 2016; Accepted: March 25, 2016; Published: March 28, 2016 
2. https://www.youtube.com/watch?v=g0MV16pVNeg\&feature $=y$ outu.be

3.https://www.youtube.com/watch?v=pUh2_MO96Q\&feature=youtu.be

\section{Discussion}

Protecting the SFG staple line to avoid bleeding and leakage is very important. Ferrer [4] cites our original work of 2005 [5,6] as we used a continuous monofilament suture to reduce the possibility of leakage and bleeding. We used to initiate the starting point with a double knot at the end of the thread, with two clips, that helped on the radiological control post-op. We were avoiding this high intra-abdominal knots in an awkward area.

We start the division of the stomach at the pylorus level. We devascularize at least $1 \mathrm{~cm}$ distal on the duodenum, and this allows us to 1) Have a free duodenum and the use the first stapler on the pylorus; 2) Pulling pylorus with a clamp that goes from right upper quadrant and aligns all to the lesser curvature above the incisura angularis and 3) This clamp is re-applied progressively in the smaller curvature in a straight line up to the esophagus gastric junction (EGJ) avoiding twists and leaving a very narrow, but straight sleeve from pylorus to the EGJ.

Daes [7] was the first to describe in 2013, and should have the credit, the use of a preformed sliding but not self-locking knot suture and Albanopoulos [8] copied the idea but the preformed knot was a non-sliding. Baltar [9] and Ferrer [10] have published work on the continuous knotted suture.

The work of our team [1,2] is the first to our knowledge that uses the self sliding-locking knot that is easily tied and it seems very appropriate to Daes [11]. We also use the greater omentum to cover the entire staple line with two purposes: 1) Cover a possible leak in the EGJ and 2) Avoid sleeve torsion anywhere on its route.

An interesting experimental study by Rogula [12] of this year shows that the continuous running suture has greater resistance to sleeve punctures and leaks. Sroka [13] has also found that the continuous suture has a lower incidence of bleeding.

Sánchez-Santos [14] has already shown that weight losses were higher with Antrectomy. Obeidat [15] demonstrated in a prospective study this year that weight loss is greater when Antrectomy is added.

\section{Conclusion}

These Videos show how to perform the self-sliding locking-knot to initiate continuous running sutures and the use of the Aberdeen-De Cushieri knot to finish them.

\section{References}

1. Serra C, Pérez N, Bou R, Baltasar A (2014) Sliding self-locking first stitch and Aberdeen knot in suture reinforcement with omentoplasty of the laparoscopic gastric sleeve staple line. Obes Surg 24: 1739-1740. [Crossref]

2. Baltasar A, Bou R, Bengochea M, Serra C, Pérez N (2015) Laparoscopic gastric sleeve, subtotal antrectomy and omentoplasty. Obes Surg 25: 195-196. [Crossref]

3. Stott PM, Ripley LG, Lavelle M A (2007) The ultimate Aberdeen knot. Ann R Coll Surg Engl 89: 713-717. [Crossref]

4. Ferrer-Márquez M, Belda-Lozano R, Ferrer-Ayza M (2012) Technical controversies in laparoscopic sleeve gastrectomy. Obes Surg 22: 182-187. [Crossref]

5. Baltasar A, Serra C, Pérez N, Bou R, Bengochea M, et al. (2005) Laparoscopic sleeve gastrectomy: a multi-purpose bariatric operation. Obes Surg 15: 1124-1128. [Crossref]

6. Serra C, Pérez N, Bou R, Bengochea M, Martínez R, et al. (2006) [Laparoscopic sleeve gastrectomy. A bariatric procedure with multiple indications]. Cir Esp 79: 289-292. [Crossref]

7. Daes J (2013) Self-locking first stitch in suture reinforcement of the laparoscopic gastric sleeve. Obes Surg 23: 794-795. [Crossref]

8. Albanopoulos K, Flessas I, Zografos G, Leandros E (2013) Self-locking first stitch in suture reinforcement of the laparoscopic gastric sleeve. Obes Surg 23: 796-797. [Crossref]

9. Baltar J, Baamonde de la Torre I (2013) Letter to Self-locking stitch in suture reinforcement of the laparoscopic gastric sleeve. Obes Surg 23: 2109. [Crossref]

10. Ferrer M, Solvas MJ, Belda R, Moreno PM, Ferrer MA (2013) The noose. A new resource in intra-corporeal laparoscopic suturing. BMI 1.1.5: 17-19. [Crossref]

11. Daes J (2014) Letter to Sliding Self-Locking First Stitch and Aberdeen Knot in Suture Reinforcement with Omentoplasty Of The Laparoscopic Gastric Sleeve Staple Line. Obes Surg 24: 10. [Crossref]

12. Rogula T, Khorgami Z, Bazan M, Mamolea C, Acquafresca P, et al. (2015) Comparison of Reinforcement Techniques Using Suture on Staple-Line in Sleeve Gastrectomy. Obes Surg 25: 2219-2224. [Crossref]

13. Sroka G, Milevski D, Shteinberg D, Mady H, Matter I (2015) Minimizing Hemorrhagic Complications in Laparoscopic Sleeve Gastrectomy-a Randomized Controlled Trial Obes Surg 25: 1577-1583. [Crossref]

14. Sánchez-Santos R, Masdevall C, Baltasar A, Martínez-Blázquez C, García Ruiz de Gordejuela A, et al. (2009) Short- and mid-term outcomes of sleeve gastrectomy for morbid obesity: the experience of the Spanish National Registry. Obes Surg 19: $1203-$ 1210. [Crossref]

15. Obeidat F, Shanti H, Mismar A, Albsoul N, Al-Qudah M (2015) The Magnitude of Antral Resection in Laparoscopic Sleeve Gastrectomy and its Relationship to Excess Weight Loss. Obes Surg 25: 1928-1932. [Crossref]

Copyright: (C2016 Baltasar A. This is an open-access article distributed under the terms of the Creative Commons Attribution License, which permits unrestricted use, distribution, and reproduction in any medium, provided the original author and source are credited. 